\title{
English-to-Russian interpreting course in distance mode: Methodological issues and curriculum implementation challenges
}

\author{
Irina V. Tivyaeva - Albina A. Vodyanitskaya
}

DOI: 10.18355/XL.2021.14.01.09

\begin{abstract}
As Covid19 spread around the world causing national lockdowns, millions of school and university students had to continue their studies in distance mode. The unplanned shift to online learning turned out to be a challenge to educators in many fields, the most problematic spheres being those that conventionally rely on face-to-face interactions. University programs in interpreting were among the worst affected ones as interpreter training requires conference equipment, direct tutor guidance and long hours of individual and group work. Adapting a graduate course in consecutive interpreting to the online format highlighted a number of methodological issues and curriculum limitations related to the specifics of the digital learning environment. Following a case-study design, this paper presents an in-depth analysis of positive and negative factors of mid-term transition to distant mode in interpreter training with a special emphasis on methodological and technological aspects of synchronous online teaching. In exploring the efficiency of the new format, the study relies on a threephase research procedure developed to monitor the transition process on the basis of pre-start screening, progress tracking and final evaluation data. The set of methods and tools employed to obtain and analyze research data includes student questionnaires, regular class observations, student self-assessment reports, open discussions and retrospective protocols. The study uses qualitative analysis in order to gain insights into advantages and disadvantages of the new format and assess its application perspectives. The findings suggest for a blended model and a need for developing the concept of digital didactics.
\end{abstract}

Key words: COVID-19, interpreter training, distance mode, online course, university curriculum

\section{Introduction}

The year 2020 will enter history textbooks as a life-changer affecting all spheres and all social groups. While the long-term aftermath of the corona crisis on economy and social life is yet to be assessed by experts in the respective fields, its here-and-now effect on the education system is already tangible. On the one hand, the sharp shift to distance mode exposed a number of issues related to technical infrastructure of schools, universities, and households, digital incompetence of teachers and lecturers, student indolence, and curriculum inflexibility, while on the other, it also offered solutions and new opportunities to introduce diversity into the education process and increase its efficiency. One cannot deny that with many issues being common to all educators who have faced the corona crisis, a great number of problems are specific to region, culture, level of education, the subject being taught, etc.

As long as it concerns the education process whether at the school or university level, the lockdown crisis has a unique standing as shifting to distance mode has not previously been the subject of intense debate among scholars. Distance learning has been on the stage for several decades now, but until recently it has been a complementary activity or an alternative option, but never the only available format of getting education. A considerable amount of literature published during the 19902010s approaches various aspects of distant and online learning (see, for instance, Garrison, Anderson, 2003; Chinnery, 2005; Dudeney, Hockly, 2007; Alipichev et al.,

XLinguae, Volume 14 Issue 1, January 2021, ISSN 1337-8384, eISSN 2453-711X 
2017; Klimova et al., 2017), but the existing accounts do not address the new challenges educators are facing today.

At present, literature is emerging that offers findings and opinions on teaching under corona-imposed conditions (see, for instance, Khatoony, Nezhdamehr, 2020; Mohmmed et al., 2020; Morris et al., 2020). A debate is taking place among those supporting the pandemic teaching mode and those who are utterly against it. The discussions are dominated mostly by theoretical reasoning and arguments concerning the potential and drawbacks of the education system in general while the teaching community is in desperate need of at least some solutions that would allow progressing with their students.

This research addresses the demand for practical solutions and offers some practiceoriented insights that may be of value to university lecturers teaching courses in interpreting and translation. The authors' ideas and suggestions are based on the experience of mid-term emergency shift of an on-site English-to-Russian interpreting course taught to first-year graduate students to the online format. The paper designed as a case study focuses on methodological issues and curriculum challenges aiming to provide a hands-on approach to online interpreter training.

Recent research has explicitly demonstrated that modern industry requires new approaches to interpreter training and linguist training in general (Suleimanova et al., 2019; Tareva 2011, 2014; Tareva, Galskova, 2013). New models rely on both innovative instruction concepts and advanced training techniques involving latest technological developments. Although interpreter training has always been perceived both by tutors and professional interpreters as an 'on-site only' area dependent on face-to-face interaction between all parties to the educational process (Kalinin, 2017; Yeskindirova, Alshinbayeva, 2017), a number of experiments were described in special literature that implemented different models of distant delivering of interpreting courses, working in virtual classes and learning environments (Mayor \& Ivars 2007; Panagiotis et al., 2012; Biernacka, 2018), exploring virtual worlds (Sahin, 2014), using online repositories and resources (Ko, 2006; Ko, 2008; Kurz, 1999), among many others.

The existing accounts are of great value to all trainers, and they could become a source of inspiration for future experiments, however, they fail to provide a solution to the corona-driven challenge faced by university tutors teaching interpreting courses. The research to date has tended to focus on the role of technology in etraining while there is much more to training interpreters online than technological advancements designed to deliver and distribute course materials. Student indolence and distress, digital skills, curriculum composition, control methods, to mention just a few of related issues.

Obviously, technology is a great asset in interpreter training (see, for instance, Melchor et al., 2020; Prandi, 2020; Spinolo, 2020) as well as in the interpreter's work. Spinolo and Amato (2020) point out three ways in which technology affects the interpreting industry: extended use of professional tools and sources, terminology management and information retrieval via Computer Assisted Interpreting tools and shifting from on-site to remote interpreting. Despite the obvious advantages, the use of technology is still limited to certain contexts and formats. In interpreter training it is specifically employed for delivering course content, engaging students in some kind of training activities and tracking progress. A comprehensive list of Computer Assisted Interpreter Training (CAIT) solutions is presented in (Kajzer-Wietrzny, Tymczyńska, 2014). Analyzing their training potential, the researchers conclude that CAIT tools are becoming integral part of interpreter education and technology is getting integrated into both in-class and out-of-class settings (Kajzer-Wietrzny, Tymczyńska, 2014).

XLinguae, Volume 14 Issue 1, January 2021, ISSN 1337-8384, eISSN 2453-711X 
The unprecedented impact of technology in interpreter education manifests itself in various interpreter training courses available on the Internet. Online interpreter training has recently become part of the Internet-based mass education segment, a variety of courses and programs being offered by prominent universities, private interpreting schools, professional interpreter associations, and online education giants like Coursera and Udacity. The seeming abundance of offers on the market creates an impression of a solid methodological basis for planning and delivering an online interpreting course and availability of ready-made solutions for tutors. A variety of available resources, some of them in free access, adds up to the illusion.

Content analysis of available resources allows for at least two reasons why none of the Internet-based courses could be used as a model in training Master's degree students. The issues are primarily related to methodology and curriculum.

The shift to online learning presupposed scheduled online meetings in which students are expected to work synchronously as a group while available online courses are designed for individual progressing and include a modest interactional component, if any at all. Therefore, asynchronous student-oriented (rather than synchronous grouporiented) tasks do not exactly match the course format.

Another issue with online courses is that their content does not meet standards of university curricula. They may be topic- or method-focused (for example, courses for medical or court interpreters aimed at preparing their students for a certification test, or courses for telephone interpreters as described in Jaime Pérez, 2018), intended for an audience without any prior training in interpreting or translation (courses for students with a high level of proficiency in foreign languages), etc. In the latter case, an online interpreting course could actually be a signboard for a practical English course presented as part of a larger professional training program (Ivanova, Tivyaeva, 2015).

A special note should be made about interpreter training programs made available by leading universities (see, for instance, (Rodríguez, 2020) for a case study of the SHIFT Summer School of Remote Interpreting held by University of Bologna in 2018). While providing a professionally designed curriculum and an advanced distant learning management system, they still do not offer any degree programs delivered online, but rather provide access to modules for self-study. Currently, there is little research available on designing all-online graduate programs in interpreting - a gap that is likely to be filled in the near post-Covid future since all-online degree programs in translation have already been successfully launched at the university level as stated in (Bilic, 2020).

Thus, a review of available Internet-based interpreting courses reveals that their standard format cannot be transferred and integrated into an online course intended for Master's degree students, which adds to the relevance of the procedure below.

\section{Methodology}

In accordance with the curriculum, at Moscow City University the English-to-Russian interpreting course is offered to first-year graduate students studying for the Master's degree in linguistics and majoring in translation and intercultural communication. The course began in the second semester of the 2019/2020 academic year and continued for four full weeks before the corona-conditioned lockdown was imposed and the channel of student-to-tutor interaction changed. To provide for the continuous implementation of the curriculum, the course was shifted to the online format, specifically, to the Microsoft Teams platform that offers a fully-equipped online working space for students and teachers. Class meetings were held regularly in strict accordance with the pre-pandemic on-campus schedule. Besides that, the Microsoft Teams platform was used for sharing additional course materials, assigning home tasks, and monitoring students' progress. Other digital resources included an online

XLinguae, Volume 14 Issue 1, January 2021, ISSN 1337-8384, eISSN 2453-711X 
microphone service and ORCIT (Online Resources for Conference Interpreter Training).

In the course of adapting the on-site interpreting course to the online format, the following goals were set: 1) testing technical infrastructure, including hardware and software, both on the tutor and the student parts, exploring technical limitations and new available options; 2) revising the curriculum content, substituting or redesigning items that could be implemented only in online mode; 3 ) developing strategies for online adjustment of regular training methods and techniques; 4) probing for new relevant teaching resources and opportunities of any kind made available by the online format; 5) monitoring students' involvement and progress in relation to the new studying mode.

The general transition-to-online strategy was focused on preserving as much as possible of the original format. The efficiency of the completed shift was evaluated on the basis of several parameters, including 1) tackling technical issues, 2) creating an effective learning environment for interpreter training in the new virtual setting, 3) student involvement and progress.

The study was conducted within the qualitative research framework and relied on a research procedure implemented in three stages. Stage 1 - Pre-Start Screening preceded the shift to the online format and was initiated as soon as relocation to the learning setting was announced. Stage 2 - Progress Tracking - consisted in regular class observation and performance evaluation on the weekly basis. The final stage included overall performance assessment.

The participants of the study were first-year graduate students $(n=13)$ working towards their Master's degree in linguistics at Moscow City University. All of the students held Bachelor's degrees in linguistics, philology or foreign languages, that is, had some prior training in English-to-Russian and Russian-to-English interpreting (at least at the elementary level). Some also had part-time jobs that listed translation or interpreting skills as a qualification requirement. Therefore, the trainees were a highly motivated and professionally competent group of students.

The methods and analysis tools used to obtain data in this research included student questionnaires, regular class observations, student self-assessment reports, open discussions, and retrospective protocols. Questionnaires were provided via Google forms within three days after the new training model was introduced at the university and were further maintained until the end of the semester. Questions on the list concerned all relevant aspects of learning in distant mode and could be classified into three categories: technical issues, course design, self-evaluation and psychological adaptation. Regular class observations and open discussions took place on the weekly basis and relied on video recordings of each online session. Retrospective protocols focused on pedagogical techniques and course design while student self-assessment reports offered insight into their expectations and progress.

\section{Results}

The results of the emergency transition to distant mode, contrary to early expectations and contrary to many voices from the linguistic community declaring the impossibility of training interpreters under online conditions, turned out to be positive in many ways, although it cannot be denied that a number of negative effects also surfaced. Some of them could be neutralized, at least partially, while others are still in need of optimal solutions. They are listed below in the sequence of goals set out in the previous section.

\section{Technical issues}

Testing the new technical infrastructure disclosed a number of limitations. The major advantage of the Microsoft Teams platform lies with the fact that it supports

XLinguae, Volume 14 Issue 1, January 2021, ISSN 1337-8384, eISSN 2453-711X 
synchronous interaction with students. As mentioned above, interpreter training options offered online do not presuppose any direct involvement between the trainer and trainees. In other words, other interpreting courses are taught in asynchronic mode, which brings the two parties apart both in time and in space. The video conference format did not allow that gap to appear.

However, data obtained from students' questionnaires and open discussions with the educators reveals that minor issues related to technical conditions of online training turned out to be major inconveniences both for students and tutors. One is obvious and not in any way specific to Microsoft Teams - unstable Internet connection was a problem to all parties. Local problems with sound and microphone took place in the first or second week of studying in distant mode, but were soon under control. Another potential problem was related to modest digital experience (which was partly expected as pre-start screening suggested lack of interacting in virtual environments), however, getting acquainted with the new learning space was smooth and did not take long, which was, among other factors, also due to emergency online training sessions offered by the university to all students and tutors as well as to interpreting community support provided via Internet forums, Facebook groups and specialized online-based events (a good example would be webinars organized by Russia's Translation Teachers Association).

The problems listed above were observed in the initial phase of the transition process that lasted for about two weeks and were easily resolved which was also confirmed by students reports.

A major technical problem was derived from the specifics of interpreter training. Working individually via a video conference deprived students of access to conference equipment and imposed certain restrictions on interaction forms commonly employed in interpreting courses. The limitations were an obstacle to working in pairs and parallel interpreting via the Bosch interpretation system used in the on-site training process. This serious disadvantage could hardly find a satisfactory solution under the given consequences, so the only methodologically justified way of dealing with it required finding workarounds, which incurred modifications of the curriculum.

\section{Curriculum and methodology challenges}

As the format-imposed technical limitations affected an important component of the interpreter training program, dropping it would result in non-completed items on the curriculum, so an appropriate substitute procedure had to be developed and introduced into the training course. The affected component consisted in practicing consecutive interpreting via specific exercises and techniques which could not be applied during online training sessions. Below is a list of format-induced curriculum challenges and suggested solutions: 1 . Impossible to continue with regular practices of taking notes. Use the taking note training system available on the ORCIT website. 2. Impossible to continue with memory drills. - Use the self-recording option of an online recording service. 3. Impossible to continue working with the Bosch interpretation system. Use the self-recording option of an online recording service and combine with analytical work. In these three cases an alternative solution was successfully found without any damage to the resulting performance.

The most problematic item on the curriculum was consecutive interpreting practice that could not be neglected as developing skills in conference interpreting is one of the major objectives of the course and it takes a great amount of the course hours. The suggested solution introduced minor modifications into the original course plan and included the following steps: 1) expanding the theoretical part of the course via a) revising theory presented in (Suleimanova et al., 2012); b) expanding the analytical component by studying parallel English and Russian transcripts of political speeches

XLinguae, Volume 14 Issue 1, January 2021, ISSN 1337-8384, eISSN 2453-711X 
and their translations and focusing on language structures relevant in interpreting (e.g. speech compression; 2) engaging students in practice-oriented events for interpretersto-be (e.g. webinars and online discussions); 3) introducing students to industry by encouraging them to participate in online professional meetings; 4) involving students in professional competitions (e.g. translation contests); 5) practice working with digital tools (e.g. remote interpreting software). In this way, the practical component of the training was still in place, but provided in an unusual format.

It should be mentioned here that the problem of practicing conference interpreting skills was immediately addressed by the professional community of interpreting trainers who faced similar issues whatever their choice of the specific learning space and instruction principles was. A response came from the Association of Translation Teachers (http://translation-teachers.ru) of which the authors are proud members. The Association brings together translation and interpreting instructors from Russia, offering professional advice and support. Some of the implemented solutions were inspired by discussion sessions and didactic webinars organized by the Association.

Methods and techniques used in training were also subject of professional and open discussions with students, and certain approaches had to be revised in order to be in line with the new format. The most obvious innovation is expanding the inventory of online tools and digital methods used in training. Another modification of the original format concerned the balance between class work and homework: while the on-site time was originally intended for more practicing with the home time being mostly used for reading and analytical work, remote mode required that a lot of analytical tasks be resolved during conference sessions. Thus, curriculum modifications, not all of them being a compromise, have affected the choice of appropriate teaching techniques as well.

\section{New opportunities and students' involvement}

Time limits and the emergency scenario activated when shifting to remote teaching mode, put a lot of pressure on instructors who had to develop digital confidence and adjust their teaching materials and training styles to the online format. This part of the shifting procedure was most rewarding as it brought about exposition to new online resources. Introduction of new tools was enthusiastically received by students as it worked both for their interpreting competence and professionally oriented digital skills.

Students' involvement in class activities increased as compared to the pre-pandemic figures, which was manifested, first, in attendance indicators, and, second, in students' participation in class activities. By the end of the semester the students have all successfully completed the course and demonstrated the level of professional skills comparable to those of the preceding year.

A new trend in student involvement could be observed: while the regular period structure underwent certain modifications, with more efforts focusing on digital resources, students' interest in online tools and new interaction forms resulted in their spending more time on extracurricular activities of professional relevance, such as attending open online lectures or webinars initiated by industry representatives or instructors from other universities.

\section{Discussion}

It is common knowledge among language mediators that recent developments and technological breakthroughs have created new professional contexts for translators and interpreters (Kosciałkowska-Okonska, 2019). Keeping up with the pace requires both working and training flexibility. To meet the demands of modern consumers of interpreting services, educators need to be aware of global trends in the industry and ready to adjust course contents in order to provide desirable learning outcomes. The

XLinguae, Volume 14 Issue 1, January 2021, ISSN 1337-8384, eISSN 2453-711X 
Covid-19 pandemic changed the perspective of interpreter education foregrounding the mode of course delivering and implementing along with its content and curriculum. This paper focuses on the authors' experience of training prospective interpreters in all-online mode and highlights both general issues the academia had to face and specific challenges that required selective approaches.

The obvious negative effect of the new learning environment consists in lack of faceto-face interaction between the trainer and trainees, which results in psychological and emotional discomfort for both parties. The obvious solution to this predicament seems to lie in redefining the roles of both the tutor and the student as suggested in (KajzerWietrzny,Tymczynska, 2014). Being in control of the learning process, trainers need more flexibility in adapting to new roles and conditions (Kosciałkowska-Okonska, 2019), while students are granted more autonomy in order to learn managing their study time and practicing (Kelly, 2005).

Technical limitations imposed by the system also contribute to the disadvantages list of the all-online format in general. However, the negative effect could be neutralized, at least partially, when efficient workarounds were found. The data extracted from student questionnaires and open discussions clearly demonstrates the need for further research into available technologies and tools, specifically into the BYOD (bring your own device) concept, in order to develop general guidelines for trainers and trainees. The importance of conducting research on available tools and working out industrial standards is also accentuated in (Spinolo 2020; Naimushin, Stepanova, 2018).

The major challenge of the teaching situation presented in this case study was to keep all items on the curriculum, which was successfully implemented with only minor modifications related to rebalancing of theoretical (analytical) and practical components. An obvious advantage of the expanded theoretical part is that students get a rare chance to discuss theoretical aspects with peers and see their application in practice, thus making a step towards eliminating the gap between theory and practice often observed in interpreter and translator training (Wadensjo, 2011; Fedyuchenko, 2018; Kosciałkowska-Okonska, 2019; Di Mango, 2019).

Two more curriculum modifications implemented under the new training conditions exposition to industry professionals and working with digital tools - also turned out to be advantages in terms of content modernization and student motivation. A strong demand for both was reported in previous research (Atabekova et al., 2018), however, university curricula are not always flexible when it comes to rapid change, so an emergency shift to a certain extent could be seen as a positive impetus.

Another positive aftereffect of transition to online mode could be seen in developing professional competences as well as soft skills required for off-site remote interpreting, which has recently become a trend in delivering interpreting services as suggested by Nimdzi Insights' market research (Nimdzi, Insights, 2020), and, according to Spinolo and Amato (2020), has been accelerated by the COVID-19 pandemic. Thus, the findings presented in this study are generally in line with global trends in education and in the interpreter training specifically. The obvious consequence of the shift to virtual classrooms both for students and instructors is the opportunity to re-evaluate traditional methods and approaches and design a new training model that would be effective in providing the market with competent practitioners committed to high-quality interpreting in any setting.

\section{Conclusion}

The global outbreak of Covid19 in early 2020 has affected all spheres of social and economic activity and brought about new realities to everyday lives of millions. The world had to make an emergency overnight shift to distant mode of working, learning, and living. As a result, the education system found itself in an awkward situation: on the one hand, educators have years of experience in delivering courses online, while

XLinguae, Volume 14 Issue 1, January 2021, ISSN 1337-8384, eISSN 2453-711X 
on the other, many of those in the teaching and tutoring were utterly unprepared for the transition.

The unplanned transition to remote work mode seen by many educators as a disaster did affect the training process on all levels, universities being no exception, however, semester-long teaching experience under new circumstances suggests that positioning the shift as a threat to high-quality education would certainly be an overstatement. As any change in a system, it triggers both positive and negative effects, the former including new digital skills and learning experience, expanded curriculum, exposure to innovative teaching technology, and new monitoring systems, the latter concerning mostly technical inconveniences and psychological issues.

The results of the case study presented in this paper reveal that despite its obvious limitations, remote mode of interpreter training relying on regular synchronous video sessions offers trainers and trainees a flexible didactic toolset that can help minimize possible faults conditioned by the online format. The emerging training environment will undoubtedly promote digital competences and professional flexibility of both Master's degree students and their instructors.

\section{Bibliographic references}

ALIPICHEV, A.Yu. - KHALEVINA, S.N. - TRUBCHENINOVA, A.A. FEDULOVA, A.N. 2017. Practical Solutions to Foreign Language Training Courses Implemented Using Distance Learning Tools. International Electronic Journal of Mathematics Education, vol. 12, n. 1, pp. 59-68. ISSN 2468-4945.

ATABEKOVA, A.A. - GORBATENIKO, R.G. - SHOUSTIKOVA, T.V. GARCES, C.V. 2018. Academia's thought and graduates' opinions of education at university degree for translators and interpreters: is there a need for revisiting both concept and practice? In: XLinguae, vol. 11, n. 1, pp. 269-283. eISSN 2453-711X.

BIERNACKA, A. 2018. Virtual Classes as an Innovative Tool for Conference Interpreter Training. In: E-mentor, vol. 77, n. 5, pp. 30-35. ISSN 1731-7428.

BILIC, V. 2020. The online computer-assisted translation classroom. In: The International Journal for Translation \& Interpreting Research, vol. 12, n. 1, pp.127141. ISSN 1836-9324

CHINNERY, G. M. 2005. 'Speaking and Listening Online'. In: English teaching forum, vol. 43, n. 3, pp. 10-16. ISSN 8755-0393.

DI MANGO, D. 2019. Does Teaching Theory Enhance Students' Translation Competence? Viewpoints, Expectations, Findings. In: inTRAlinea Special Issue: New Insights into Translator Training. Available online:

http://www.intralinea.org/specials/article/2425. ISSN 1827-000X

DUDENEY, G. - HOCKLY, N. 2007. How to teach English with technology,

Harlow: Pearson Education Limited. ISBN 978-1405853088.

FEDYUCHENKO, L.G. 2018. Practical knowledge vs translation theory: assessment of students' knowledge. In: XLinguae, vol. 11, n. 3, pp. 114-125. eISSN 2453-711X.

GARRISON, D. R. - ANDERSON, T. 2003. E-learning in the 21st Century, London: Routledge/Falmer. ISBN 9780203166093.

IVANOVA, V. - TIVYAEVA, I. 2015. Teaching foreign languages in Soviet and present-day Russia: a comparison of two systems. In: Zbornik Instituta za Pedagoska Istrazivanja, vol. 47, n. 2, pp. 184-192. ISSN 0579-6431.

JAIME PEREZ, A. 2018. Designing and Implementing an Online Training Programme for Telephone Interpreters. In: Approaches to telephone interpretation: research, innovation, teaching and transference. Berna, Peter Lang, pp. 33-50.

ISBN:978-3-0343-3105-0

KAJZER-WIETRZNY, M. - TYMCZYNSKA, M. 2014. Integrating Technology into Interpreter Training Courses: A Blended Learning Approach. In: inTRAlinea Special

XLinguae, Volume 14 Issue 1, January 2021, ISSN 1337-8384, eISSN 2453-711X 
Issue: Challenges in Translation Pedagogy. Available online: http://www.intralinea.org/specials/article/2101. ISSN 1827-000X

KALININ, A.Yu. 2017. Information and communication technology in interpreter training: e-tools and multimedia content. In: PNRPU Linguistics and Pedagogy Bulletin, vol. 2, pp. 131-139. ISSN 2305-140X.

KELLY, D. 2005. A Handbook of Translator Trainers. Manchester, St Jerome Publishing. ISBN: 978-1900650816

KHATOONY, SH. - NEZHADMEHR, M. 2020. EFL Teachers' Challenges in the Integration of Technology for Online Classrooms during Coronavirus (COVID-19) Pandemic in Iran. In: The Asian Journal of English Language \& Pedagogy, vol. 9, Special Issue COVID-19, pp. 1-16. ISSN 2289-8689.

KLIMOVA, I. - KALUGINA, O. - KHALEVINA, S. - FEDULOVA, A. TRUBCHENINOVA, A. 2017. Investigating effective foreign language learning design and the implications for distance learning tools. In: XLinguae, vol. 10, n. 3, pp. 273-284. eISSN 2453-711X.

KO, L. 2006. Teaching interpreting by distance mode: Possibilities and constraints. In: Interpreting, vol. 8, n. 1, pp. 67-96. E-ISSN 1569-982X.

KO, L. 2008. Teaching Interpreting by Distance Mode: An Empirical Study. In: Meta, vol. 53, n. 4, pp. 814-840. ISSN 1492-1421.

KOSCIAŁKOWSKA-OKONSKA, E. 2019. Translation as a profession: training the new generation. In: inTRAlinea Special Issue: New Insights into Translator Training. Available online: http://www.intralinea.org/specials/article/2426. ISSN 1827-000X

KURZ, I. 1999. Remote conference interpreting: Assessing the technology. In: Lugris, A.A., Ocampo, A.F. (eds.) Anovar/anosar estudios de tranduccion e interpretacion, Servicio de Publicacion da Universidade de Vigo, pp. 114-116. ISBN 84-8158-139-9.

LEE, S.-B. 2019. Holistic assessment of consecutive interpretation. In: Interpreting, vol. 21:22, pp. 245-269. E-ISSN 1569-982X

MAYOR, M. - IVARS, A. 2007. E-Learning for interpreting. In: Babel, vol. 53, n. 4, pp. 292-302. E-ISSN 1569-9668.

MOHMMED, A. - KHIDIR, B. - NAZEER, D. - VIJAYAN, V. 2020. Emergency remote teaching during Coronavirus pandemic: the current trend and future directive at Middle East College Oman. In: Innovative Infrastructure Solutions, vol. 5, 72. ISSN 2364-4184.

MELCHOR, M. - HORVATH, I. - FERGUSON, K. 2020. The Role of Technology in Conference Interpreter Training. Oxford, Bern, Berlin, Bruxelles, New York, Wien: Peter Lang. ISBN: 978-1-788874-407.

MORRIS, S. - ROTHMAN, J.R. - OWENS, J. 2020. Introduction to the Special Section: Teaching During a Pandemic. In: Literacies \& Language Education: Research \& Practice. English Language Institute, KUIS, pp. 1-6.

NAIMUSHIN, B. - STEPANOVA, M. 2018. The Association of Translator and Interpreter Trainers: Building a Network of Teaching Excellence. In: Society and Languages in the Third Millennium. Communication. Education. Translation. RUDN University, Moscow, pp. 169-178.

NIMDZI INSIGHTS. 2020. Interpreting in times of Covide-19. Available online: https://www.nimdzi.com/interpreting-in-times-of-covid-19/

PANAGIOTIS, R. - GETTING, R. - ROBERTS, R. - BRAUN, S. - SLATER, C. 2012. Using virtual reality for interpreter-mediated communication and training. In: Cyberworlds. Proceedings of the International Conference. Darmstadt, pp. 191-198.

PRANDI, B. 2020. The use of CAI tools in interpreter training: where are we now and where do we go from here? In: inTRAlinea Special Issue: Technology in Interpreter Education and Practice. Available online: http://www.intralinea.org/specials/article/2512. ISSN 1827-000X

XLinguae, Volume 14 Issue 1, January 2021, ISSN 1337-8384, eISSN 2453-711X 
RODRIGUEZ, M. 2020. La interpretación a distancia y su formación: la experiencia de la Shift Summer School y cómo crear la 'virtualidad necesaria' en el aula. In: inTRAlinea Special Issue: Technology in Interpreter Education and Practice. Available online: http://www.intralinea.org/specials/article/2514. ISSN 1827-000X SAHIN, M. 2014. Virtual Worlds in Interpreter Training. In: The Interpreter and Translator Trainer, vol. 7, n. 1, pp. 91-106.

SEEBER, K.G. - KELLER, L. - AMOS, Rh. - HENGLE, S. Expectations vs. experience. Attitudes towards video remote conference interpreting. In: Interpreting, vol 21 (2), pp. 270-304. E-ISSN 1569-982X

SPINOLO, N. - AMATO, A.A. 2020. Technology in Interpreter Education and Practice: Introduction. In: inTRAlinea Special Issue: Technology in Interpreter Education and Practice. Available online: http://www.intralinea.org/specials/article/2520_. ISSN 1827-000X

SPINOLO, N. 2020. Nuevas tecnologías para la transmisión de la interpretación simultanea: una revolución ya en marcha. In: inTRAlinea Special Issue: Technology in Interpreter Education and Practice. Available online: http://www.intralinea.org/specials/article/2516. ISSN 1827-000X

SULEIMANOVA, O.A. - BEKLEMESHEVA, N.N. - KARDANOVA, K.S. LYAGUSHKINA, N.V. - YAREMENKO, V.I. 2012. Grammaticheskie aspekty perevoda. Moscow: Academia. ISBN 978-5-7695-8740-5.

SULEIMANOVA, O.A. - NERSESOVA, E.V. - VISHNEVSKAYA, E.M. 2019. Technologicheskii aspekt podgotovki sovremennogo perevodchika. In: Filologicheskie nauki. Voprosy teorii i praktiki, vol. 12, n. 7, pp. 313-317. ISSN 19972911.

TAREVA, E.G. 2011. Mezhkul'turnyi podhod k podgotovke sovremennyh lingvistov. In: Problemy teorii, praktiki i didaktiki perevoda. Sbornik nauchnyh trudov. Yazyk, kul'tura, kommunikatsiya. Nizhnii Novgorod: Nizhnii Novgorod State Linguistic University, pp. 237-244. ISBN 978-5-85839-219-4.

TAREVA, E.G. 2014. Kommunikativnyi podhod: v poiskah lingvodidakticheskih innovatsiy. In: Pedagogicheskoe obrazovanie i nauka, vol. 5, pp. 98-103. ISSN 20722524.

TAREVA, E.G. - GALSKOVA, N.D. 2013. Innovatsii v obuchenii yazyku i kul'ture: pro et contra. In: Innostrannye yazyki v shkole, vol. 10, pp. 2-8. ISSN 0130-6073.

YESKINDIROVA, M.ZH. - ALSHINBAYEVA, ZH.K. 2017. Methodology of simultaneous translation: some strategies and features. In: XLinguae, vol. 10, n. 4, pp. 196-208. eISSN 2453-711X.

WADENSJO, C. 2011. Interpreting in theory and practice. Reflections about an alleged gap. In: Methods and strategies of process research: Integrative approaches in translaiton studies. Amsterdam, John Benjamins, pp. 13-21. ISBN 9789027224422

Words: 5286

Characters: 37797 (21,11 standard pages)

Prof. Irina Tivyaeva

Assoc. Prof. Albina Vodyanitskaya

Department of Linguistics and Translation Studies

Institute of Foreign Languages

Moscow City University

4-1, $2^{\text {nd }}$ Sel'skokhozyajstvennyj proezd, 129226, Moscow

Russian Federation

TivyaevaIV@mgpu.ru

VodyanickayaAA@mgpu.ru

XLinguae, Volume 14 Issue 1, January 2021, ISSN 1337-8384, eISSN 2453-711X 